\title{
PREDICTING THE PSYCHOLOGICAL WELL-BEING OF DENTALSTUDENTS DURING THE SEMESTER EVALUATION PERIOD: A PROSPECTIVE STUDY
}

\author{
Cristina Teodora Preoteasa ${ }^{1 a}$, Marian-Vladimir Constantinescu ${ }^{2 b^{*}}$, Elena Preoteasa ${ }^{3 \mathrm{c}}$ \\ 'Department of Oral Diagnosis, Ergonomics, Scientific Research Methodology, Faculty of Dental Medicine, "Carol Davila" University \\ of Medicine and Pharmacy, Bucharest, Romania \\ ${ }^{2}$ ROPOSTURO - Holistic Dental Medicine Institute, Bucharest, Romania \\ ${ }^{3}$ Department of Prosthodontics, Faculty of Dental Medicine, "Carol Davila" University of Medicine and Pharmacy, Bucharest, Romania \\ ${ }^{\mathrm{D} D M D}$, PhD, Assistant Professor \\ ${ }^{b} \mathrm{DDS}$, PhD, Professor \\ 'DMD, PhD, Professor
}

Received: February 27, 2016

Received in revised form: March 4, 2016

Accepted: April 21, 2016

Cite this article:

Published online: February 27, 2016

Preoteasa CT, Constantinescu M-V, Preoteasa E. Predicting the psychological well-being of dental students during the semester evaluation period: a prospective study. Stoma Edu J. 2016;3(1-2):47-53.

Aim: The study aimed at monitoring the psychological well-being of dental students over the first semester of the academic year, in order to acknowledge if psychological well-being during the semester evaluation period is predicted by well-being during teaching period.

Methodology: Second year dental students from the Faculty of Dental Medicine, "Carol Davila" University of Medicine and Pharmacy, Bucharest, Romania were evaluated across the first academic semester, on three consecutive times during the teaching period, and one time during the semester evaluation evaluation period. Well-being was evaluated in terms of subjective positive psychological well-being, assessed by WHO-Five Well-being Index (WHO-5), and as the severity of depression symptoms, assessed by Major Depression Inventory (MDI).

Results: As expected, the students' psychological well-being was highest at the beginning of the semester and lowest during the semester evaluation period. By regression analysis it was observed that wellbeing during the semester evaluation period is poorly predicted by their well-being at the beginning of the semester, and it is better predicted when assessed in similar periods with regard to the quality of stressors (i.e., written examinations) or at the end of the teaching period. Also, their psychological wellbeing in terms of severity of depression symptoms seems to be a more predictable state than subjective positive psychological well-being.

Conclusion: Early identification of students at high risk to exhibit lowering levels of psychological wellbeing should be implemented in order to plan the necessary interventions to help students cope with the examination distress and prevent its unwanted consequences.

Keywords: education, stress, risk, mental health, prevention.

\section{Introduction}

Subjective psychological well-being is seen as a component of the general construct of well-being with great impact on everyday life, on the ability to identify and fulfil goals, to adapt and cope with the environment. ${ }^{1,2}$

Evidence suggests that the educational process in the medical and dental schools associates a somehow inherent distress, which might have an inadvertent negative effect on the students' well-being, with probable short and long-term consequences, e.g. may affect the academic performance, is a risk factor for anxiety, depression and burnout, is linked to behavioural patterns and health of the future doctors. ${ }^{3,4}$ Keeping in mind that the basic aim of education is to train knowledge, efforts need to be made in order to identify the most adequate ways to implement it. 5,6 Since a negative side effect of the educational process on the student's psychological health is suspected, further high quality research is needed in order to understand the problem's magnitude, aetiology, prognosis, and if necessary to identify the best diagnostic and interventional approaches.

The aim of this study was to monitor the psychological well-being of second year dental students during the first semester of the academic year, in order to acknowledge if the psychological well-being during the semester evaluation period is predicted by well-being during the teaching period. 
Table 1. Student's positive well-being, assessed by WHO-5 scores, over the first semester of the academic year

\begin{tabular}{|c|c|c|c|}
\hline Time & Students & WH0-5 score (mean) & $p$ \\
\hline \multirow{3}{*}{$\mathrm{T} 1$} & All & 66 & \multirow{12}{*}{$\begin{array}{l}\text { All (T1:T2): } 0.038^{*} \\
\text { All (T2:T3): } 0.136 \\
\text { All (T3:T4): } 0.009^{\star} \\
\text { All (T1:T4): } 0.014^{*} \\
\text { Male: Female (T1): } 0.523 \\
\text { Male: Female (T2): } 0.103 \\
\text { Male: Female (T3): } 0.805 \\
\text { Male: Female (T4): } 0.084 \\
\text { From Bucharest: Other (T1): } 0.203 \\
\text { From Bucharest: Other (T2): } 0.667 \\
\text { From Bucharest: Other (T3): } 0.249 \\
\text { From Bucharest: Other (T4): } 0.529\end{array}$} \\
\hline & Male: Female & $65: 66$ & \\
\hline & From Bucharest: Other & $70: 65$ & \\
\hline \multirow{3}{*}{$\mathrm{T} 2$} & All & 62 & \\
\hline & Male: Female & $66: 60$ & \\
\hline & From Bucharest: Other & 63: 61 & \\
\hline \multirow{3}{*}{$\mathrm{T} 3$} & All & 65 & \\
\hline & Male: Female & $64: 65$ & \\
\hline & From Bucharest: Other & 69: 64 & \\
\hline \multirow{3}{*}{$\mathrm{T} 4$} & All & 58 & \\
\hline & Male: Female & $65: 55$ & \\
\hline & From Bucharest: Other & $60: 57$ & \\
\hline
\end{tabular}

\section{Materials and Methods}

This study was approved by the Ethics Committee for Scientific Research at the "Carol Davila" University of Medicine and Pharmacy, Bucharest, Romania (PO-35-F-03, No. 55).

\subsection{Study design and settings}

A prospective study was designed and implemented on a cohort of second year dental students from the Faculty of Dental Medicine, "Carol Davila" University of Medicine and Pharmacy, Bucharest, Romania. Data were collected during the first semester of the 2014-2015 academic year (from October $1^{\text {st }} 2014$ to February $15^{\text {th }} 2015$ ), three consecutive times during the teaching period and one time during the semester exam period.

\subsection{Subjects}

One series of second year dental students who attended the above-mentioned university was enrolled in this study. Enrolment was done considering all eligible subjects, who voluntarily agree to participate in this study. Repeaters and transferred students were excluded, because their courses are partially different from those of regular students, having usually less or more subjects to attend. All participants were informed upon the main characteristics of this study and a written informed consent was granted, in the beginning, and also in the follow-up appointments.

\subsection{Variables}

The main study outcome was the subjective psychological well-being, assessed using the WHO-Five Well-being Index (WHO-5) and the Major Depression Inventory (MDI). The Romanian language version of both questionnaires was used. The Romanian language version of $\mathrm{WHO}-5$ that was used was the one available on the website dedicate to this index, that of the Psychiatric Research Unit (Mental Health Centre North Zealand, Hillerod, Denmark). The index has been previously tested and demonstrated to have good psychometric properties as a well-being scale and as a screening instrument for depression. ${ }^{7}$ The Romanian language version of MDI that was used was the one available in the Romanian guide for adult depression for general practitioners. Other study variables were demographics (age, sex) and origin (from Bucharest or other). The latter was chosen on the idea that students from Bucharest experience less life changes, usually preserving their living accommodation and the relations with their family and friends.

\subsection{Data collection}

Data were collected by administering a written questionnaire before or after classes, its timing being related to the academic activities, as favouring different levels of stress, as follows: $\mathrm{T} 1-2^{\text {nd }}$ week of the teaching period, corresponding to the beginning of the first academic semester;

$\mathrm{T} 2-7^{\text {th }}$ week of the teaching period, corresponding to its middle, during which half-semester theoretical examinations are scheduled for some of the courses taken; the questionnaire was filled just after a written examination;

T3 $-13^{\text {th }}$ week of the teaching period, that was just after the Christmas and New Year break, corresponding to the end of the teaching period, when students have practical examinations for the seminars activities of most of the courses taken; the questionnaire was filled just after a practical examination;

T4 $-4^{\text {th }}$ week (last week) of the semester exam period; the questionnaire was administered just after a written examination.

\subsection{Statistical methods}

Missing data, caused by not fully filling the questionnaire all four times, were managed by excluding the subject from the analysis.

Data analysis included frequency distributions, Wilcoxon test, paired t-test, Mann-Whitney test and unpaired t-test. Change in well-being was assessed by change of WHO-5 score and MDI score. The difference of $\mathrm{WHO}-5$ scores of at least 10 , considered as a clinically significant change 
Table 2. Change of positive well-being over the first academic semester

\begin{tabular}{|c|c|c|c|c|}
\hline \multirow{2}{*}{ Well-being change } & \multirow{2}{*}{ WHO-5 score change (mean) } & \multicolumn{3}{|c|}{ Clinically significant change of well-being } \\
\cline { 3 - 5 } & 3.88 & Improvement & No change & Worsening \\
\hline In T2 compared to T1 & -2.91 & $17(24 \%)$ & $24(24 \%)$ & $29(41 \%)$ \\
\hline In T3 compared to T2 & 6.74 & $22(31 \%)$ & $36(51 \%)$ & $12(17 \%)$ \\
\hline In T4 compared to T3 & 7.71 & $11(16 \%)$ & $32(46 \%)$ & $27(39 \%)$ \\
\hline In T4 compared to T1 & $18(26 \%)$ & $19(27 \%)$ & $33(47 \%)$ \\
\hline
\end{tabular}

Table 3. Student's well-being, assessed by MDI scores, over the first semester of the academic year

\begin{tabular}{|c|c|c|c|}
\hline Time & Students & MDI score (mean) & $\mathrm{p}$ \\
\hline \multirow{3}{*}{$\mathrm{T} 1$} & All & 10 & \multirow{12}{*}{$\begin{array}{l}\text { All (T1:T2): } 0.004^{\star} \\
\text { All (T2:T3): } 0.637 \\
\text { All (T3:T4): } 0.261 \\
\text { All (T1:T4): <0.001* } \\
\text { Male: Female (T1): } 0.194 \\
\text { Male: Female (T2): } 0.082 \\
\text { Male: Female (T3): } 0.681 \\
\text { Male: Female (T4): } 0.174 \\
\text { From Bucharest: Other (T1): } 0.229 \\
\text { From Bucharest: Other (T2): } 0.710 \\
\text { From Bucharest: Other (T3): } 0.799 \\
\text { From Bucharest: Other (T4): } 0.810\end{array}$} \\
\hline & Male: Female & 9:11 & \\
\hline & From Bucharest: Other & 9:11 & \\
\hline \multirow{3}{*}{ T2 } & All & 13 & \\
\hline & Male: Female & $11: 14$ & \\
\hline & From Bucharest: Other & $13: 13$ & \\
\hline \multirow{3}{*}{ T3 } & All & 13 & \\
\hline & Male: Female & 13:13 & \\
\hline & From Bucharest: Other & $12: 13$ & \\
\hline \multirow{3}{*}{ T4 } & All & 15 & \\
\hline & Male: Female & 13:15 & \\
\hline & From Bucharest: Other & $14: 14$ & \\
\hline
\end{tabular}

in well-being, was recorded on an ordinal scale (improvement; no change; worsening). Regression analysis was performed in order to assess if wellbeing during the teaching period (in T1, T2, T3) predicts well-being during examination period (in T4). SPSS Statistics was used to perform the statistical analysis. Significance was set at $p<0.05$ (significance level 95\%) for all statistical tests. p-value less than 0.05 as marked by "*".

\section{Results}

The selected series included ninety-two dental students, out of which eighty-five met the eligibility criteria and all agreed to participate in this research. Seventy of them (response rate of $82 \%$ ) filled the questionnaires all four times. Most of them were females $(n=49 ; 70 \%)$, twenty years old $(n=57$; $81 \%$ ). Fifteen (21\%) students were from Bucharest. The students' well-being during the first academic semester. The students' well-being exhibited changes during the first academic semester, in terms of subjective positive psychological wellbeing, assessed by WHO-5 score, but also as the severity of depression symptoms, assessed by the MDI score. Observing the WHO-5 scores, a statistically significant reduction of well-being was noticed during the first half of the semester (at T2 compared to T1), followed by a not statistically significant increase of it after a twoweek holiday (at T3 compared to T2). In the winter exam period (at T4), as expected, a statistically significant reduction in the students' well-being was observed, which reached its lowest level. A subgroup analysis showed that male students and Bucharest natives registered higher $\mathrm{WHO}-5$ scores during the written exam period (at T2 and T4), which means better well-being, at a level that was not statistically significant (Table 1). Considering the difference of WHO-5score out of 10, assessed as a clinically significant change in positive wellbeing, at almost all moments in time frequent changes in the positive well-being were noticed, with either improvement or worsening. Only ten students did not show a clinically significant change in the positive well-being when assessed at two consecutive times, across the entire semester. About $40 \%$ of the students registered a clinically significant worsening of their positive well-being during the written exam period (at T2 compared to T1; at T4 compared to T3). Over the entire first semester (T4 compared to T1) almost half of the students registered a clinically significant worsening of their positive well-being (Table 2). With respect to the MDI scores, a statistically significant reduction of well-being was noticed during the first half of the semester teaching period (at T2 compared to T1), that continued afterwards, at a level that was not statistically significant. A subgroup analysis showed that during the written exam period female students (T2 and T4) had a tendency of registering higher MDI scores, meaning higher severity of depression symptoms (Table 3 ). Classifying students according to the MDI score obtained, there were 6 students in T1, 8 students in T2, 13 students in T3 and 17 students in T4 with MDI scores $\geq 20$, regarded as having depression. Consequently, the ratio between mild to moderate to severe depression was the following: $2: 3: 1$ in $T 1 ; 3: 3: 2$ in $T 2 ; 7: 2: 4$ in T3; 7:5:5 in T4. Prediction of subjective well- 
Table 4. Bivariate regression results for students' well-being during teaching period predicting wellbeing during semester examination period

\begin{tabular}{|c|l|c|c|c|c|c|}
\hline \multirow{2}{*}{ Dependent variable } & \multicolumn{1}{|c|}{ Independent variable } & $\mathrm{B}$ & $\mathrm{t}(69)$ & $\mathrm{R}^{2}$ & $\mathrm{~F}(1,69)$ & $\mathrm{p}$ \\
\hline \multirow{3}{*}{ WHO-5 in T4 } & WHO-5 in T1 & 0.13 & 1.05 & 0.02 & 1.10 & 0.298 \\
\cline { 2 - 7 } & WHO-5 in T2 & 0.52 & 5.04 & 0.27 & 25.36 & $<0.001$ \\
\cline { 2 - 7 } & WHO-5 in T3 & 0.43 & 3.93 & 0.17 & 15.45 & $<0.001$ \\
\hline \multirow{3}{*}{ MDI in T4 } & MDI in T1 & 0.38 & 3.35 & 0.14 & 11.20 & 0.001 \\
\cline { 2 - 7 } & MDI in T2 & 0.72 & 8.51 & 0.51 & 72.37 & $<0.001$ \\
\cline { 2 - 7 } & MDI in T3 & 0.69 & 7.88 & 0.48 & 62.04 & $<0.001$ \\
\hline
\end{tabular}

being during the semester evaluation period by well-being during the teaching period. Regression analysis showed that psychological well-being during the semester evaluation period (T4) is poorly predicted by the psychological well-being at the beginning of the first academic semester (T1). Even so, psychological well-being (i.e. both the positive psychological well-being assessed by the $\mathrm{WHO}-5$ scores and the severity of depression symptoms assessed by the MDI score) during the semester evaluation period (T4) seems to be more accurately predicted by their well-being during similar periods with respect to the quality of the stressors, i.e. written examination (T2), or at the end of the teaching period (T3). Also, the psychological well-being in terms of severity of depression symptoms seems an aspect that is more predictable than subjective the positive psychological well-being. (Table 4).

\section{Discussion}

The level of psychological well-being in dental and medical students was previously reported by several studies to be reduced compared to the population norms, being most probably related to the identified high level of stress, reported as present in about one in three dental students. ${ }^{4,8}$ This study results suggest reduced levels of positive psychological well-being in dental students, compared to the general population (i.e., of approximately 70, when measured by WHO$5), 9,10$ especially during the semester evaluation period. Two cross-sectional studies evaluating well-being using WHO-5 on samples formed by dental students from Europe were identified, i.e. one from Munich, Germany, reporting WHO5 scores of about 55,11 and one from Budapest, Hungary, reporting scores of $\mathrm{WHO}-5$ of $58 .{ }^{12}$ Both found the WHO- 5 scores for dental students below 70 , but it is difficult to compare the results of those studies to those of the current study considering the exact moment for data collection, with regard to the academic year progress, as it was not clearly specified in the two prior studies. Regarding the variation in the students' MDI scores, it was noticed that at the beginning of the academic semester the frequency of depression was rather similar compared to the general population in Europe, i.e. of approximately $8.56 \% .^{13}$ Even so, over the academic semester the frequency of depression increased, reaching its highest level during the semester evaluation period (24\%), to a level closer to the one reported by Ibrahim et al. for university students (30.6\%). ${ }^{14}$ According to current knowledge, the association between stress and examinations is predictable, as they are believed to act as an acute stressor, and to have a cumulative effect. ${ }^{15,16}$ This aspect is supported by our study especially for the written examinations, which are associated to a higher decrease in the students' level of wellbeing. Other prospective research, on dental students, suggests that there can be an increase in the stress perceived over the academic year, that is suspected to have detrimental effects on performance and health. ${ }^{17-19}$ Stressors perceived by students' and their effects most probably are different among dental schools, being related to a mix of factors, including individual and institutional parameters, but also geographic and socio-demographic patterns, Romanian dental students being previously identified as experiencing a high perceived stress level. ${ }^{20-23}$ The decrease in the level of well-being should be counted considering several aspects: subjective well-being predicts objective mental health, may impact on the learning performance, may bias the student's evaluation and have negative long-term effects, e.g., emotional problems such as depression, may limit and impact the future professional practice. 9,10,24 As concerns were raised with respect to the decreased wellbeing of the dental students, the inherent distress that exists and its negative effect at a personal and learning level, recommendations were made to help students to cultivate their skills to sustain their well-being, through formal and informal offerings within medical school. ${ }^{25-27}$ According to this study's results, students at high risk of reduced levels of well-being during the semester evaluation period may be initially identified during other periods over the semester with written examinations, and interventions for coping with examination stress at the most demanding times of the academic year may be planned accordingly. Also, positive and negative psychological states are generally seen as related, but independent constructs of well-being. Our results suggest that negative wellbeing is a more predictable state that positive well-being, therefore better knowledge of the impact of academic stressors and their longterm effect on each of them, separately, may be necessary to be understood, in order to have a clearer idea on this phenomenon. Regarding the instruments used for data collection, for positive and negative psychological states, some details 
about them are given in this paragraph. WHO-5 is an instrument developed by the World Health Organization, which measures self-reported positive psychological well-being. WHO-5 consists of a 5-item questionnaire, positively worded, with a time frame of previous two weeks. Its interpretation is in accordance to the score obtained, that ranges from 0 to 100 percentage score, where higher score means better well-being.

To monitor change, a difference of $\mathrm{WHO}-5$ percentage score out of 10 is considered clinically significant. 9,10,28,29 $\mathrm{MDI}$ is also an instrument developed by the World Health Organization, and in this study it is used as a self-rating depression scale. It consists of a 10-item questionnaire, two of them having two alternative questions. It has a similar time frame, of previous two weeks. Its interpretation is in accordance to the score obtained, that ranges from 0 to 50 . MDI results were recorded as scale score (where high score means higher severity of depression symptoms), were dichotomized according to the cut-off value of $\geq 20$ into likely depression or not, and were recorded on an ordinal scale (mild depression: 20 to 24; moderate depression: 25 to 29; severe depression: $\geq 30$ ). ${ }^{30}$

Study limitations include the possibility that results are biased by specific factors of the population that the sample was drown, thus results need to be confirmed by studies implemented in other dental schools. Also, a deeper analysis, considering all years of study, effects on academic performance and health, through high quality prospective research is recommended.

\section{Conclusions}

The psychological well-being of the dental students decreases over the first semester of the academic year, reaching its lowest point during the semester evaluation period. The students' well-being during the semester evaluation period seems to be poorly predicted by well-being at the beginning of the academic year, and it is better to assess it in similar periods with regard to the quality of the stressors (i.e. written examinations) or at the end of the teaching period. Considering the fact that medical training in general requires an increased number of examinations taken over a large time-interval, that may associate a cumulative reduction of well-being, the early identification of students at high risk to exhibit lowering levels of psychological well-being should be implemented in order to plan the necessary interventions to help students cope with the examination distress and prevent its unwanted consequences.

\section{Acknowledgements}

This research was supported by a postdoctoral fellowship from the project "Programme of excellency in multidisciplinary doctoral and postdoctoral research of chronic diseases", contract no. POSDRU/159/1.5/S/133377, project co-financed by the European Social Fund through the Sectoral Operational Programme for Human Resources Development (SOP HRD) 2007-2013.

\section{REFERENCES}

1. Chen FF, Jing $Y$, Hayes $A$, Lee JM. Two concepts or two approaches? A bifactor analysis of psychological and subjective wellbeing. J Happiness Stud. 2013;14(3): 1033-1068.

2. Vazquez C, Hervas G, Rahona JJ, Gomez D. Psychological well-being and health: Contributions of positive psychology. Annuary of clinical and health psychology. 2009;5:15-27.

3. Dyrbye LN, Thomas MR, Shanafelt TD. Systematic review of depression, anxiety, and other indicators of psychological distress among U.S. and Canadian medical students. Acad Med. 2006;81(4):354-373.

4. Elani HW, Allison PJ, Kumar RA, Mancini L, Lambrou A, Bedos C. A systematic review of stress in dental students. J Dent Educ. 2014;78(2):226-242.

5. Harikiran AG, Srinagesh J, Nagesh KS, Sajudeen N. Perceived sources of stress amongst final year dental under graduate students in a dental teaching institution at Bangalore, India: a cross sectional study. Indian J Dent Res. 2012;23(3):331-336. 6. Iacopino AM, Pryor ME, Taft TB, Lynch DP. The effect of NIDCR R25 grant support on the curriculum and culture of a research non-intensive dental school. J Dent Res. 2007;86(7):581-585. 7. Preoteasa CT, Preoteasa E. Psychometric properties of romanian version of who- 5 well-being index in dental students. Romanian Journal of Oral Rehabilitation. 2015;7(3):21-27.
8. Aboalshamat K, Hou XY, Strodl E. Psychological well-being status among medical and dental students in Makkah, Saudi Arabia: a cross-sectional study. Med Teach. 2015;37 Suppl 1:S75-S81.

9. Bech P. Subjective positive well-being. World Psychiatry 2012;11(2):105-106.

10. Bech P. Clinical Psychometrics. Oxford: Wiley-Blackwell; 2012. 11. Möller-Leimkühler AM, Yücel M. Male depression in females? J Affect Disord 2010;121(1-2):22-29.

12. Köteles F, Simor P. Modern health worries, somatosensory amplification, health anxiety, and well-being. A cross-sectional Study. Eur J Mental Health. 2014;9(1):20-33.

13. Ayuso-Mateos JL, Vázquez-Barquero JL, Dowrick C, Lehtinen V, Dalgard OS, Casey P, Wilkinson C, Lasa L, Page H, Dunn G, Wilkinson G; ODIN Group. Depressive disorders in Europe: prevalence figures from the ODIN study. $\mathrm{Br} J$ Psychiatry. 2001;179:308-316.

14. Ibrahim AK, Kelly SJ, Adams CE, Glazebrook C. A systematic review of studies of depression prevalence in university students. J Psychiatr Res. 2013;47(3):391-400.

15. Alzahem AM, van der Molen HT, Alaujan AH, Schmidt HG, Zamakhshary MH. Stress amongst dental students: a systematic review. Eur J Dent Educ. 2011;15(1):8-18. 
16. Naidu RS, Adams JS, Simeon D, Persad S. Sources of stress and psychological disturbance among dental students in the West Indies. J Dent Educ. 2002;66(9):1021-1030.

17. Birks Y, McKendree J, Watt I. Emotional intelligence and perceived stress in healthcare students: a multi-institutional, multi-professional survey. BMC Med Educ. 2009;9:61.

18. Silverstein ST, Kritz-Silverstein D. A longitudinal study of stress in first-year dental students. J Dent Educ. 2010;74(8):836-848.

19. Yusoff MS, Abdul Rahim AF, Baba AA, Ismail SB, Mat Pa MN, Esa AR. The impact of medical education on psychological health of students: a cohort study. Psychol Health Med. 2013;18(4):420-430.

20. Polychronopoulou A, Divaris K. Dental students' perceived sources of stress: a multi-country study. J Dent Educ. 2009; 73(5):631-639.

21. Pau A, Rowland ML, Naidoo S, AbdulKadir R, Makrynika E, Moraru R, Huang B, Croucher R. Emotional intelligence and perceived stress in dental undergraduates: a multinational survey. J Dent Educ. 2007;71(2):197-204.

22. Preoteasa CT, Mircescu G, Buzea MC, Preoteasa E. Sources of stress and well-being in dental students. Romanian Journal of Oral Rehabilitation. 2015;7(3):28-32.

23. Preoteasa CT, Imre M, Preoteasa E. Dental students' psychological well-being during examination period and holiday. Rev Med Chir Soc Med Nat lasi. 2015; 119(2): 549-556.
24. Uras C, Delle Poggi A, Rocco G, Tabolli S. Psychological wellbeing and risk of anxiety/depression in nursing students measured with the General Health Questionnaire-12. Assist Inferm Ric. 2012;31(2):70-75.

25. Gustems-Carnicer J, Calderón C. Coping strategies and psychological well-being among teacher education students. Eur J Psychol Educ. 2013;28(4):1127-1140.

26. Dunn LB, Iglewicz A, Moutier C. A conceptual model of medical student well-being: promoting resilience and preventing burnout. Acad Psychiatry. 2008;32(1):44-53.

27. Kappe $\mathrm{R}$, van der Flier $\mathrm{H}$. Predicting academic success in higher education: what's more important than being smart? Eur J Psychol Educ. 2012; 27(4):605-619.

28. Singh R, Goyal M, Tiwari S, Ghildiyal A, Nattu SM, Das S. Effect of examination stress on mood, performance and cortisol levels in medical students. Indian J Physiol Pharmacol. 2012; 56(1):48-55.

29. Löwe B, Spitzer RL, Gräfe K, Kroenke K, Quenter A, Zipfel S, Buchholz C, Witte S, Herzog W. Comparative validity of three screening questionnaires for DSM-IV depressive disorders and physicians' diagnoses. J Affect Disord. 2004;78(2):131-140.

30. Thorsen SV, Rugulies R, Hjarsbech PU, Bjorner JB. The predictive value of mental health for long-term sickness absence: the Major Depression Inventory (MDI) and the Mental Health Inventory (MHI-5) compared. BMC Med Res Methodol. 2013;13:115. doi: 10.1186/1471-2288-13-115. 


\section{Cristina Teodora PREOTEASA}

DMD, PhD, Assistant Professor Department of Oral Diagnosis, Ergonomics, Scientific Research Methodology "Carol Davila" University of Medicine and Pharmacy, Bucharest, Romania

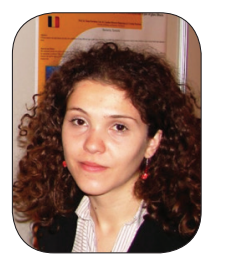

She obtained her DMD degree in 2006 from "Carol Davila" University of Medicine and Pharmacy, Bucharest, Romania. She completed a Master program in "Biocompatible substances, materials and systems" in 2008.

She became MS in Orthodontics and Dento-Facial Orthopedics in 2010.

Her PhD thesis, entitled "Clinical and experimental contributions on the interaction of orthodontic appliances with the hard structures of the teeth" was presented in 2013.

She is author/ co-author of more than 40 manuscripts in peer-review journals and book chapters in 5 books published in Romania and abroad. She participated to several national and international professional meetings, with oral and poster presentations.

Her main interests include: orthodontics, dental education, prosthodontics, oral implantology, esthetic dentistry, dental materials.

\section{Questions}

\section{Which of the following statements about the WHO-5 Well-being Index is FALSE?}

$\square$ a. Is an instrument which measures self-reported positive psychological well-being;

$\square$ b. Consists of a 5-item questionnaire, positively worded, with a time frame of previous two weeks;

c. It's interpretation is in accordance to the score obtained, where higher score means better wellbeing;

$\square$ d. To monitor change, a difference of WHO-5 percentage score of 100 is considered clinically significant.

\section{During the academic semester, dental students register the lowest level of subjec- tive psychological well-being:}

$\square$ a. At the beginning of the semester;

b. During written exam periods, other than final exams;

$\square$ c. During practical exam periods;

$\square$ d. During semester evaluation period, when final exams are taken.

\section{Dental students' subjective psychological well-being during the semester evaluation period is better predicted by:}

$\square$ a. Dental students' well-being at the beginning of the semester;

$\square$ b. Dental students' well-being in similar periods with regard to the quality of stressors (i.e., written examinations);

$\square$ c. Dental students' well-being at the end of the teaching period;

$\square \mathrm{d}$. All the above are similar as predictors.

\section{Which of the following statements regarding the dental students' well-being is FALSE?}

a. The level of their psychological well-being is higher than general population norms;

$\square$ b. Their psychological well-being in terms of the severity of the depression symptoms is more predictable than the subjective positive psychological well-being;

$\square$ c. Dental students should cultivate their skills to sustain their well-being;

$\square$ d. A decrease in their level of well-being may have short-term negative effects, e.g. may impact on the learning performance. 